\title{
The impact of CRTH2 antagonist OC 000459 on pulmonary function of asthma patients: a meta-analysis of randomized controlled trials
}

\author{
Meng Tang ${ }^{1}$, Yan Zhang ${ }^{2}$, Ying Chen ${ }^{1}$ \\ ${ }^{1}$ Department of Respiration, Xixi Hospital of Hangzhou, Hangzhou, Zhejiang, China \\ 2Department of Radiology, Xixi Hospital of Hangzhou, Hangzhou, Zhejiang, China
}

Adv Dermatol Allergol 2021; XXXVIII (4): 566-571 DOI: https://doi.org/10.5114/ada.2020.92296

\begin{abstract}
Introduction: The chemoattractant receptor expressed on T-helper (Th) type 2 cells (CRTH2) antagonist OC 000459 showed the potential in improving pulmonary function of asthma patients.

Aim: We conducted a systematic review and meta-analysis to explore the impact of CRTH2 antagonist OC 000459 on pulmonary function for asthma.

Material and methods: PubMed, Embase, Web of science, EBSCO, and Cochrane library databases were systematically searched. This meta-analysis included randomized controlled trials (RCTs) assessing the effect of CRTH2 antagonist OC 000459 on pulmonary function for asthma. Two investigators independently searched articles, extracted data, and assessed the quality of included studies.

Results: Four RCTs were included in the meta-analysis. Overall, compared with the control intervention for asthma patients, CRTH2 antagonist OC 000459 could significantly improve $\mathrm{FEV}_{1}(\mathrm{SMD}=0.22 ; 95 \% \mathrm{Cl}: 0.02-0.42 ; p=0.03)$, peak expiratory flow $(\mathrm{SMD}=0.22 ; 95 \% \mathrm{Cl}: 0.01-0.42 ; p=0.04)$ and reduce the respiratory tract infection $(\mathrm{RR}=0.47$; $95 \% \mathrm{Cl}: 0.26-0.85 ; p=0.01)$, but revealed no remarkable effect on predicted $\mathrm{FEV}_{1}(\mathrm{SMD}=0.14 ; 95 \% \mathrm{Cl}:-0.18$ to 0.45 ; $p=0.39)$, or treatment-related adverse events ( $\mathrm{RR}=0.84 ; 95 \% \mathrm{Cl}: 0.52-1.36 ; p=0.48)$.

Conclusions: CRTH2 antagonist OC 000459 might be effective and safe to improve pulmonary function in asthma patients.
\end{abstract}

Key words: CRTH2 antagonist, OC 000459, pulmonary function, asthma, randomized controlled trial.

\section{Introduction}

Asthma is well known as a serious public health problem in the world [1-3]. It is a heterogeneous disease and considerable progress and distinct phenotypes may respond differently to treatment [4-6]. During the active airway inflammation, the leukocytic infiltrate can be eosinophilic or neutrophilic or mixed. $40-50 \%$ of asthma patients are estimated to have eosinophil-dominant airway inflammation [7, 8]. The chronic inflammatory process mediated and orchestrated by products of certain immune cells leads to the clinical manifestations in these patients [9-13].
CRTH2 is a G-protein-coupled receptor expressed by Th2 lymphocytes, eosinophils and basophils. It has a dominant role in the activation of these cell types responding to the mast cell product prostaglandin D2 (PGD2), which is followed by increased cell migration and elaboration of Th2 cytokines [14-16]. CRTH2-deficient mice or animals with CRTH2 antagonists revealed the involvement of this receptor in effector responses to allergens including leucocyte accumulation, Th2 cytokine production, tissue swelling, airway hyperresponsiveness and production of IgE [17].

CRTH2 antagonist OC 000459 was documented to reduce airway inflammation, improve lung function and quality of life in moderate persistent asthma [18, 19].

Address for correspondence: Yan Zhang, Department of Radiology, Xixi Hospital of Hangzhou, No. 2 Hengbu Street, Liuxia Street, West Lake District, Hangzhou 310023, Zhejiang, China, phone/fax:+86 0571-86481777, e-mail: 3106790335@qq.com Received: 31.10.2019, accepted: 23.11.2019. 
Several RCTs have explored the efficacy of CRTH2 antagonist OC 000459 for the asthma control, but the results were inconsistent [19-21].

\section{Aim}

We therefore conducted a systematic review and meta-analysis of RCTs to evaluate the effectiveness of CRTH2 antagonist OC 000459 on asthma control.

\section{Material and methods}

This systematic review and meta-analysis were conducted according to the guidance of the Preferred Reporting Items for Systematic Reviews and Meta-analysis statement [22] and the Cochrane Handbook for Systematic Reviews of Interventions [23]. All analyses were based on previously published studies, and thus no ethical approval and patient consent were required [24].

\section{Literature search and selection criteria}

PubMed, EMbase, Web of science, EBSCO, and the Cochrane library were systematically searched from inception to September 2019, with the following key words: "CRTH2 antagonist" or "OC 000459", and "asthma". To include additional eligible studies, the reference lists of retrieved studies and relevant reviews were also handsearched and the above process was performed repeatedly until no further article was identified.

The inclusion criteria were as follows: (1) patients were diagnosed with chronic asthma; (2) intervention treatments were CRTH2 antagonist OC 000459 versus placebo; (3) the study design was RCT.

\section{Data extraction and outcome measures}

The following information was extracted for the included RCTs: first author, publication year, sample size, forced expiratory volume in $1 \mathrm{~s}\left(\mathrm{FEV}_{1}\right)$, Predicted $\mathrm{FEV}_{1}$ and detailed methods in two groups, etc. The author would be contacted to acquire the data when necessary.

The primary outcomes were $\mathrm{FEV}_{1}$ change, and predicted $\mathrm{FEV}_{1}$ change. Secondary outcomes included peak expiratory flow change, respiratory tract infection and treatment-related adverse events.

\section{Quality assessment in individual studies}

The Jadad Scale was widely used to evaluate the methodological quality of each RCT included for the meta-analysis [25]. This scale consisted of three evaluation elements: randomization (0-2 points), blinding ( $0-$ 2 points), dropouts and withdrawals ( $0-1$ points). One point would be allocated to each element if they were mentioned in the article, and another point would be given if the methods of randomization and/or blinding were appropriately described. The score of Jadad Scale varied from 0 to 5 points. If the Jadad score was $\geq 3$, the study was thought to have high quality [26].

\section{Statistical analysis}

Standard Mean difference (SMD) with 95\% confidence interval $(\mathrm{Cl})$ for continuous outcomes (FEV change, predicted $\mathrm{FEV}_{1}$ change, and peak expiratory flow change) and risk ratio (RR) with $95 \% \mathrm{Cl}$ for dichotomous outcomes (respiratory tract infection and treatment-related adverse events) were used to estimate the pooled effects. The random-effects model was used for all the meta-analyses. An $l^{2}$ value greater than $50 \%$ indicated significant heterogeneity. Sensitivity analysis was performed to detect the influence of a single study on the overall estimate via omitting one study in turn when necessary. Publication bias was not assessed due to the limited number of included studies $(n<10) . P<0.05$ in two-tailed tests was considered statistically significant. All statistical analyses were performed using Review Manager (RevMan Version 5.3. Copenhagen, Nordic Cochrane Centre, Cochrane Collaboration).

\section{Results}

Literature search, study characteristics and quality assessment

The flow chart for the selection process and detailed identification was presented in Figure 1. Two hundred and eighteen publications were identified through the initial search of databases. Ultimately, four RCTs were included in the meta-analysis [18-21].

The baseline characteristics of four eligible RCTs in the meta-analysis were summarized in Table I. The four studies were published between 2012 and 2014, and the total sample size was 451 . Three studies involved OC 000459200 mg twice daily [18, 19, 21], while the remaining study involved $25 \mathrm{mg}$ once daily [20]. The treatment duration ranged from 8 days to 84 days.

Among the four RCTs, three studies reported FEV change $[18,20,21]$, and two studies reported predicted FEV ${ }_{1}$ change [18, 21], two studies reported peak expiratory flow change $[18,20]$, three studies reported respiratory tract infection and treatment-related adverse events [18-20]. Jadad scores of the four included studies varied from 3 to 5 , and all four studies were considered to have high quality.

\section{Primary outcomes: $\mathrm{FEV}_{1}$ change and predicted $\mathrm{FEV}_{1}$ change}

These two outcome data were analysed with the random-effects model. Compared to the control group for asthma patients, CRTH2 antagonist OC 000459 was associated with the increased $\mathrm{FEV}_{1}(\mathrm{SMD}=0.22 ; 95 \% \mathrm{Cl}$ : $0.02-0.42 ; p=0.03)$ with no heterogeneity among the studies $\left(I^{2}=0 \%\right.$, heterogeneity $\left.p=0.79\right)$ (Figure 2 ), 


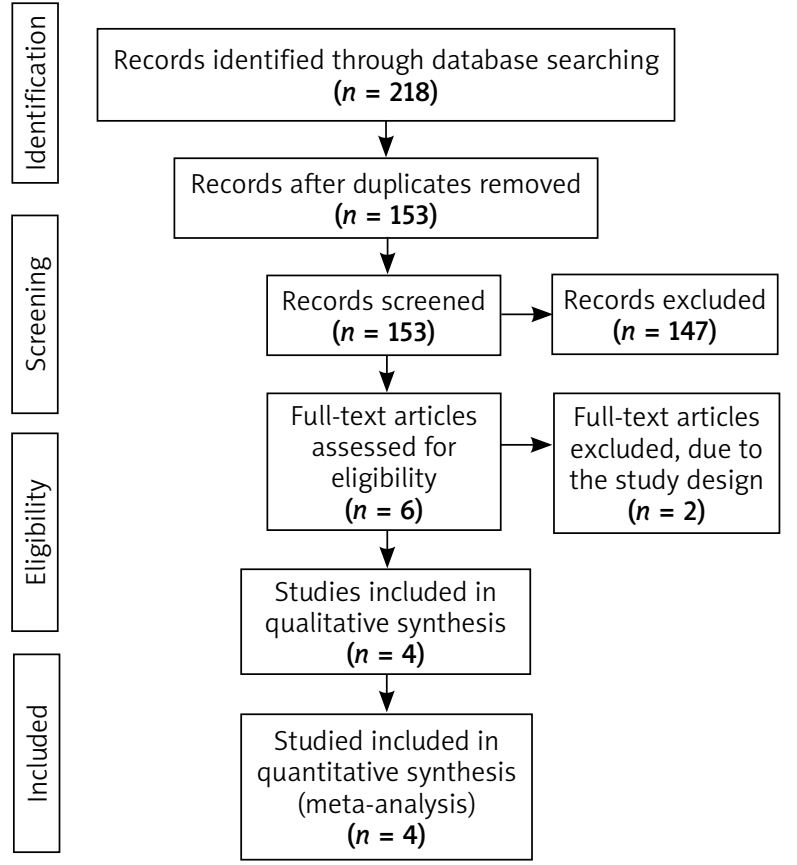

Figure 1. Flow diagram of the study search and selection process

but demonstrated no obvious effect on predicted FEV (SMD $=0.14 ; 95 \% \mathrm{Cl}:-0.18$ to $0.45 ; p=0.39)$ with no heterogeneity among the studies $\left(R^{2}=0 \%\right.$, heterogeneity $p=0.95$ ) (Figure 3).

\section{Sensitivity analysis}

No heterogeneity was observed among the included studies for the primary outcomes. Thus, we did not perform sensitivity analysis by omitting one study in each turn to detect the source of heterogeneity.

\section{Secondary outcomes}

Compared with control intervention for asthma patients, CRTH2 antagonist OC 000459 can substantially increase the peak expiratory flow $(\mathrm{SMD}=0.22 ; 95 \% \mathrm{Cl}$ : $0.01-0.42 ; p=0.04$; Figure 4 ) and reduce the respiratory tract infection $(\mathrm{RR}=0.47 ; 95 \% \mathrm{Cl}: 0.26-0.85 ; p=0.01$; Figure 5). There was no statistical difference of treatmentrelated adverse events between two groups $(R R=0.84$; 95\% Cl: 0.52-1.36; $p=0.48$; Figure 6).

\section{Discussion}

PGD2 levels were raised in patients with asthma after the allergen challenge [27-29]. CRTH2 antagonist targeting this prostanoid could inhibit airway inflammation and mucus production in the mouse and guinea pig models of asthma [30, 31]. OC 000459, an N1-indole acetic acid derivative, was one selective antagonist of CRTH2.

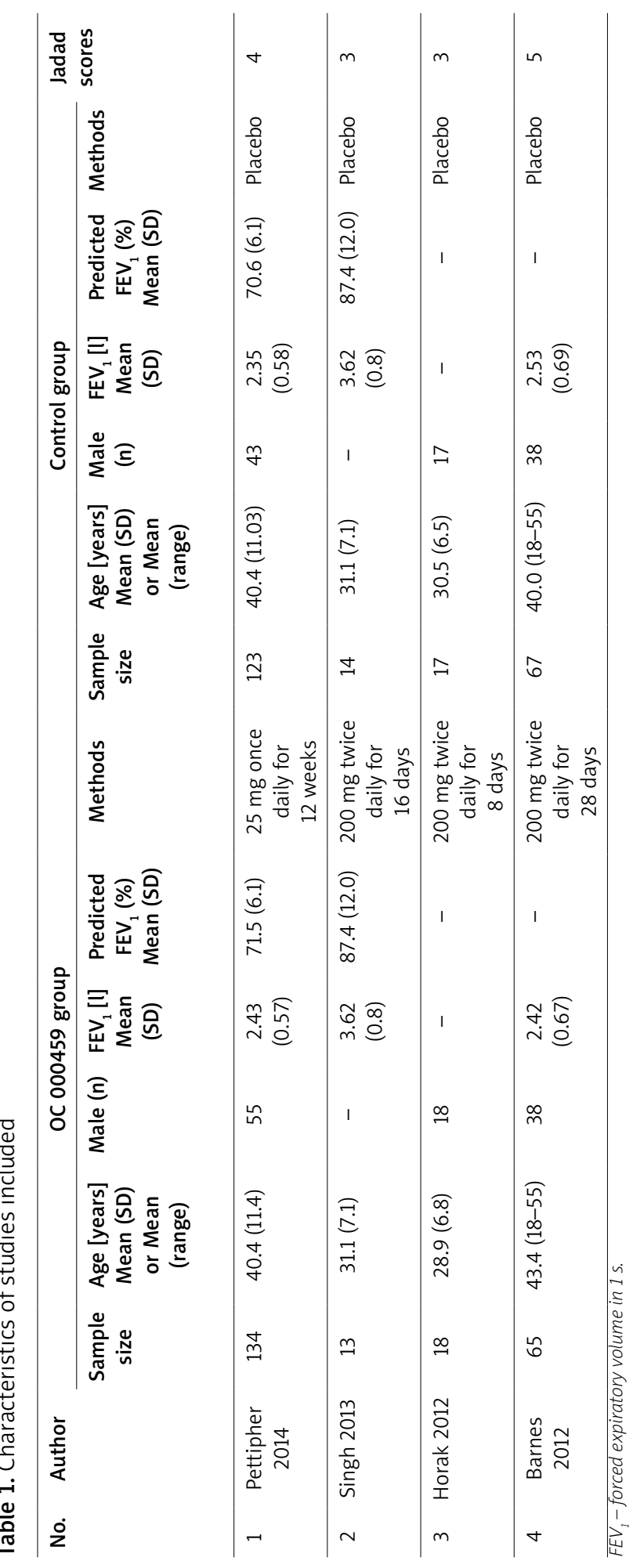

The improvement in pulmonary function was observed after 28-day OC 000459 treatment for asthma patients without inhaled corticosteroids [18].

Our meta-analysis suggested that CRTH2 antagonist OC 000459 had the capability to increase the $\mathrm{FEV}_{1}$ and 


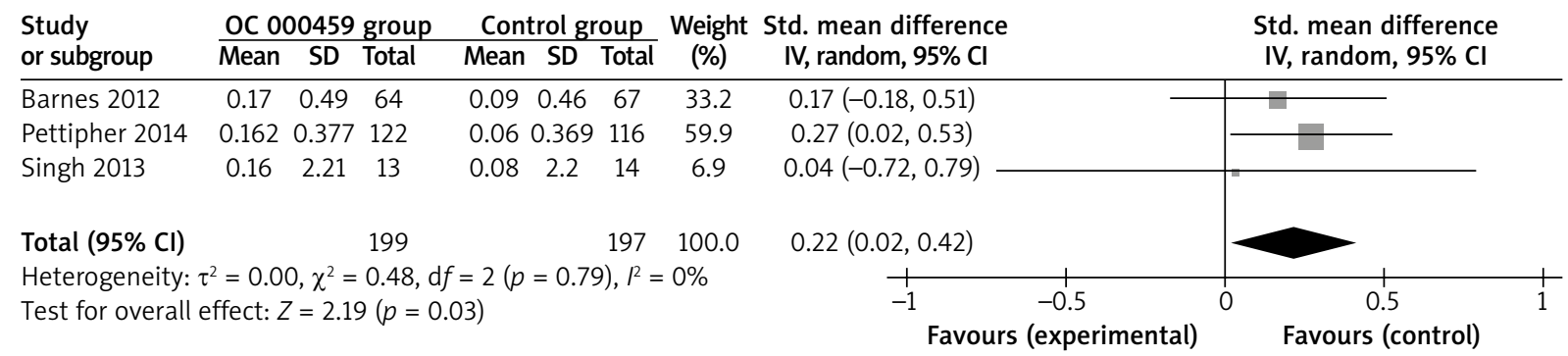

Figure 2. Forest plot for the meta-analysis of $\mathrm{FEV}_{1}$ change

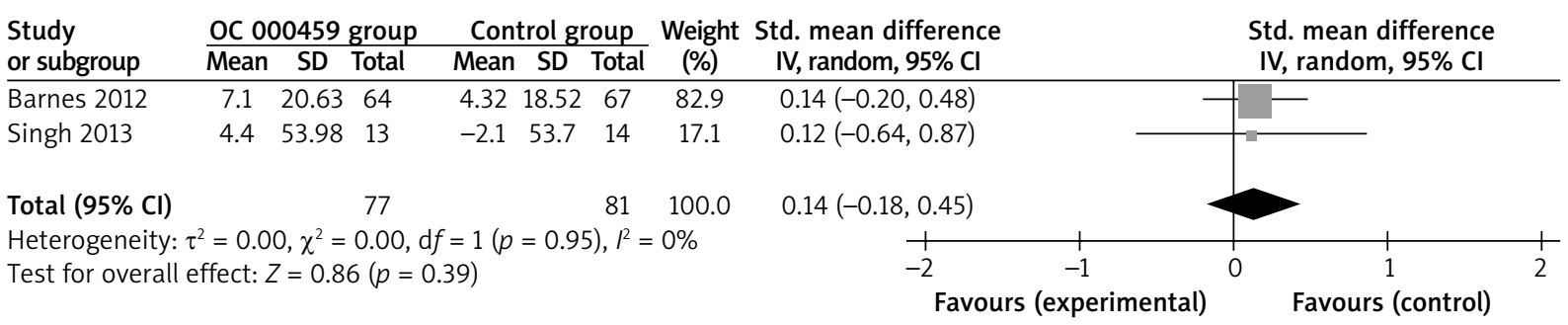

Figure 3. Forest plot for the meta-analysis of predicted $\mathrm{FEV}_{1}$ change

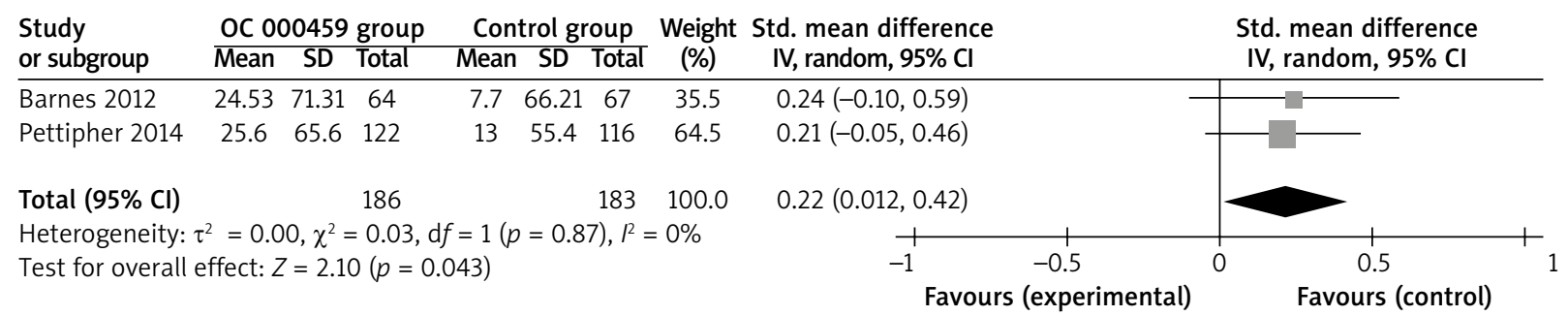

Figure 4. Forest plot for the meta-analysis of peak expiratory flow change

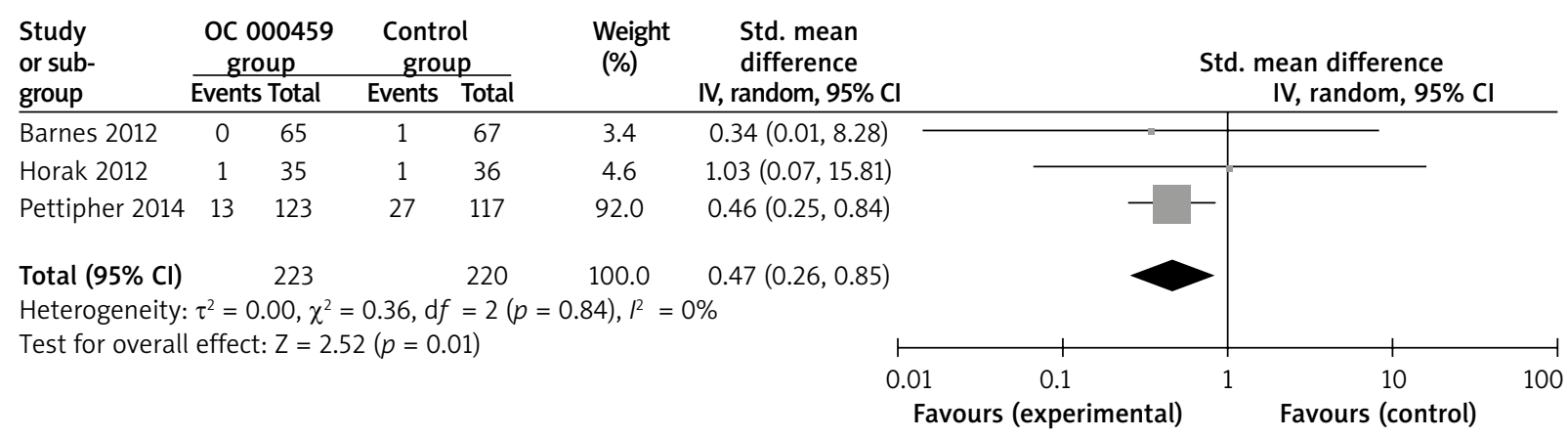

Figure 5. Forest plot for the meta-analysis of respiratory tract infection

peak expiratory flow change in asthma patients, but demonstrated no obvious effect on predicted FEV $\mathrm{COm}_{1}$ pared with placebo. In another study involving OC 000459 at three dose levels (25 mg once daily, $200 \mathrm{mg}$ once daily or $100 \mathrm{mg}$ twice daily) for 12 weeks, the efficacy of OC 000459 in improving lung function and asthma symp- toms was observed in both atopic and non-atopic asthma subjects with varying degrees of blood eosinophilia. These three dose levels of OC 000459 were all effective, and $25 \mathrm{mg}$ once daily of OC 000459 provided a higher increase in $\mathrm{FEV}_{1}$ and peak expiratory flow than the other two doses of Oc000459. $25 \mathrm{mg}$ (or less) administered 


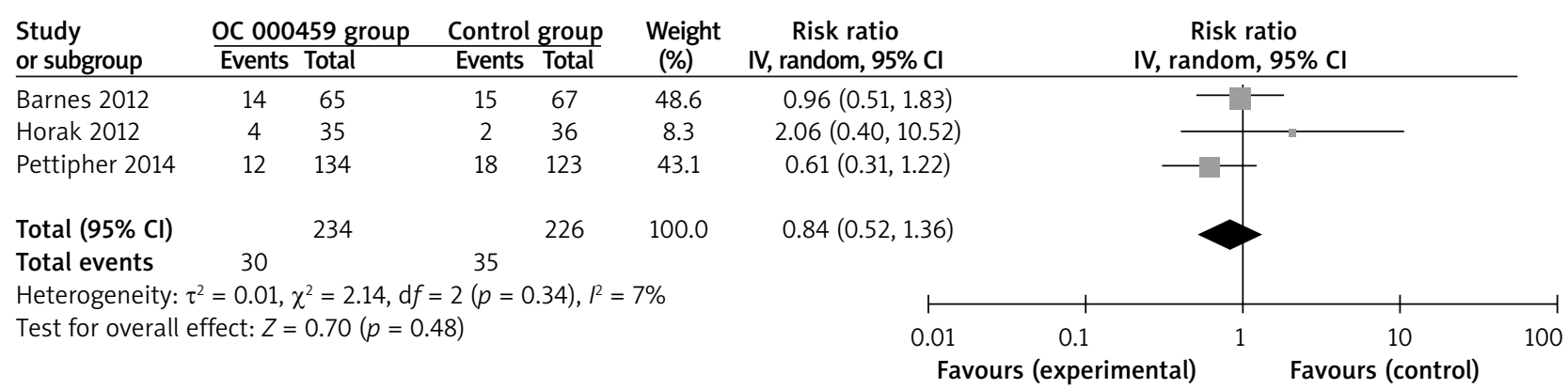

Figure 6. Forest plot for the meta-analysis of treatment-related adverse events

once daily might be sufficient to provide maximal efficacy as evidenced by the high plasma concentrations of drug detected at this dose [20].

Blood eosinophil counts might have the utility in identifying responders to anti-IL-5, anti-IL-13 and antiCRTH2 therapies, and were associated with disease severity and response to drug therapy. The geometric mean sputum eosinophil count was reduced from 2.1\% to $0.7 \%(p=0.03)$ after OC 000459 in asthma patients, but this effect was not significant in the placebo group [18]. Although there was no significant heterogeneity for the primary outcomes, different doses and treatment duration of CRTH2 antagonist OC 000459, and various severities of diseases might have some impact on the pooling results. In addition, CRTH2 antagonist OC 000459 resulted in the reduction in respiratory tract infection and no increase in the total treatment-related adverse events in our meta-analysis.

Several limitations should be taken into account. Firstly, our analysis was based on four RCTs only and two of them had a relatively small sample size $(n<100)$. Overestimation of the treatment effect was more likely in smaller trials compared with larger samples. Next, different doses and treatment duration of CRTH2 antagonist OC 000459 , and various severities of diseases might have some influence on the pooling results. Finally, it was not feasible to perform the meta-analysis of some outcomes such as exacerbation and FVC based on current RCTs.

\section{Conclusions}

CRTH2 antagonist OC 000459 might be beneficial for asthma control, and more RCTs should be conducted to confirm this issue.

\section{Conflict of interest}

The authors declare no conflict of interest.

\section{References}

1. National Heart L, Institute B. Global strategy for asthma management and prevention. http://www ginasthma com/. 2002.
2. Braman SS. The global burden of asthma. Chest 2006; 130: 4S-12S.

3. Lambrecht BN, Hammad H, Fahy JV. The cytokines of asthma. Immunity 2019; 50: 975-91.

4. Haldar P, Pavord ID, Shaw DE, et al. Cluster analysis and clinical asthma phenotypes. Am J Respir Crit Care Med 2008; 178: 218-24

5. Moore WC, Meyers DA, Wenzel SE, et al. Identification of asthma phenotypes using cluster analysis in the Severe Asthma Research Program. Am J Respir Crit Care Med 2010; 181: 315-23.

6. Siddiqui S, Shikotra A, Richardson M, et al. Airway pathological heterogeneity in asthma: visualization of disease microclusters using topological data analysis. J Allergy Clin Immunol 2018; 142: 1457-68.

7. Haldar P, Pavord ID. Noneosinophilic asthma: a distinct clinical and pathologic phenotype. J Allergy Clin Immunol 2007; 119: 1043-52.

8. McGrath KW, Icitovic N, Boushey HA, et al. A large subgroup of mild-to-moderate asthma is persistently noneosinophilic. Am J Respir Crit Care Med 2012; 185: 612-9.

9. Holgate ST. Pathogenesis of asthma. Clin Exp Allergy 2008; 38: 872-97.

10. O'Byrne PM. Cytokines or their antagonists for the treatment of asthma. Chest 2006; 130: 244-50.

11. Bergeron C, Al-Ramli W, Hamid Q. Remodeling in asthma. Proc Am Thorac Soc 2009; 6: 301-5.

12. Vuolo F, Abreu SC, Michels M, et al. Cannabidiol reduces airway inflammation and fibrosis in experimental allergic asthma. Eur J Pharmacol 2019; 843: 251-9.

13. Boulet LP. Airway remodeling in asthma: update on mechanisms and therapeutic approaches. Curr Opin Pulmon Med 2018; 24: 56-62.

14. Gyles SL, Xue L, Townsend ER, et al. A dominant role for chemoattractant receptor-homologous molecule expressed on Thelper type 2 (Th2) cells (CRTH2) in mediating chemotaxis of CRTH2+ CD4+ Th2 lymphocytes in response to mast cell supernatants. Immunology 2006; 119: 362-8.

15. Xue L, Barrow A, Pettipher R. Interaction between prostaglandin D2 and chemoattractant receptor-homologous molecule expressed on Th2 cells mediates cytokine production by Th2 lymphocytes in response to activated mast cells. Clin Exp Immunol 2009; 156: 126-33.

16. Pettipher R, Vinall SnL, Xue L, et al. Pharmacologic profile of OC000459, a potent, selective, and orally active D prostanoid receptor 2 antagonist that inhibits mast cell-dependent activation of T helper 2 lymphocytes and eosinophils. J Pharmacol Exp Ther 2012; 340: 473-82. 
17. Pettipher R, Whittaker M. Update on the development of antagonists of chemoattractant receptor-homologous molecule expressed on Th2 cells (CRTH2). From lead optimization to clinical proof-of-concept in asthma and allergic rhinitis. J Med Chem 2012; 55: 2915-31.

18. Barnes N, Pavord I, Chuchalin A, et al. A randomized, double-blind, placebo-controlled study of the CRTH2 antagonist OC000459 in moderate persistent asthma. Clin Exp Allergy 2012; 42: 38-48.

19. Horak F, Zieglmayer P, Zieglmayer R, et al. The CRTH 2 antagonist OC 000459 reduces nasal and ocular symptoms in allergic subjects exposed to grass pollen, a randomised, placebo-controlled, double-blind trial. Allergy 2012; 67: 1572-9.

20. Pettipher R, Hunter M, Perkins C, et al. Heightened response of eosinophilic asthmatic patients to the CRTH 2 antagonist OC 000459. Allergy 2014; 69: 1223-32.

21. Singh D, Cadden P, Hunter M, et al. Inhibition of the asthmatic allergen challenge response by the CRTH2 antagonist OC000459. Eur Respir J 2013; 41: 46-52.

22. Moher D, Liberati A, Tetzlaff J, Altman DG, Group P. Preferred reporting items for systematic reviews and meta-analyses: the PRISMA statement. BMJ 2009; 339: b2535.

23. Higgins JPT GS. Cochrane Handbook for Systematic Reviews of Interventions Version 5.1.0 [updated March 2011]. The Cochrane Collaboration. 2011. Available from www.cochranehandbook.org.

24.Zhao J, Huang W, Zhang S, et al. Efficacy of glutathione for patients with cystic fibrosis: a meta-analysis of randomized-controlled studies. Am J Rhinol Allergy 2019:1945892419878315.

25. Jadad AR, Moore RA, Carroll D, et al. Assessing the quality of reports of randomized clinical trials: Is blinding necessary? Control Clin Trials 1996; 17: 1-12.

26. Kjaergard LL, Villumsen J, Gluud C. Reported methodologic quality and discrepancies between large and small randomized trials in meta-analyses. Ann Intern Med 2001; 135: 982-9.

27. Domingo C, Palomares O, Sandham DA, et al. The prostaglandin D2 receptor 2 pathway in asthma: a key player in airway inflammation. Respir Res 2018; 19: 189.

28. Kao CC, Parulekar AD. Spotlight on fevipiprant and its potential in the treatment of asthma: evidence to date. J Asthma Allergy 2019; 12: 1-5.

29. Brightling CE, Brusselle G, Altman P. The impact of the prostaglandin D2 receptor 2 and its downstream effects on the pathophysiology of asthma. Allergy 2019; doi: 10.1111/ all.14001.

30. Uller L, Mathiesen JM, Alenmyr L, et al. Antagonism of the prostaglandin D2 receptor CRTH2 attenuates asthma pathology in mouse eosinophilic airway inflammation. Respir Res 2007; 8: 16.

31. Pettipher $R$. The roles of the prostaglandin D2 receptors DP1 and $\mathrm{CRTH} 2$ in promoting allergic responses. $\mathrm{Br}$ J Pharmacol 2008; 153: S191-9. 